\title{
LAS REVOLUCIONES EN AMÉRICA LATINA
}

Cristóbal Arteta Ripoll

\footnotetext{
* Magíster en Educación y Filosofía Latinoamericana (USTA), Doctorando en Filosofía (USTA), Director de la Revista Amauta, Docente investigador Universidad del Atlántico, Universidad Libre, Asesor de investigaciones Universidad Simón Bolívar. cristobalarteta@yahoo.es
} 
La primera gran revolución triunfante en América Latina se desató en Haití y condujo a la formación de un Estado Nacional.

Durante las últimas cuatro décadas del siglo XVIII Haití era la colonia más rica del mundo, con una economía agrícola productora de azúcar, café, añil y algodón, y su comercio exterior, en 1788, era superior al de Estados Unidos.

Las violentas contradicciones entre una mayoría de esclavos y una minoría de blancos, condujo a una sublevación general de esclavos el 14 de agosto de 1791.Como manifestación y ejemplo de que los blancos no permitirían fácilmente levantamientos, a lo largo de la vía que conduce al puerto de Cap Français, fueron colgados más de diez mil negros como escarnio público.

El emperador francés, Napoleón, envió a la isla a más de veinte mil veteranos de guerra el 29 de enero de 1802, quienes arrasaron y destruyeron todo lo que encontraban en su camino, hasta que lograron pactar con el ejército de François Dominique Toussaint Lovertoure, pero luego lo traicionaron y lo enviaron preso a Francia.

La traición aceleró el proceso independentista y las tropas francesas tuvieron que abandonar a Saint-Domingue, el 4 de diciembre de 1803, proclamándose la independencia el 1 de enero de 1804, y el nombre de la colonia fue cambiado por el de Haití. De esa manera, se aseguró la libertad de los negros, el reparto de tierras y la creación del Estado.

\section{LEVANTAMIENTOS A PARTIR DE 1780}

En el territorio de la civilización inca, bajo la dirección de Túpac Amaru y Túpac Catari y paralelamente a la guerra de inde- 
pendencia de las trece colonias de América del Norte, se desarrolló la gran insurrección de independencia en territorio peruano, donde la radicalidad del campensinado indígena jugó un papel de primer orden.

Esa insurrección sentó las bases y desbrozó el camino de una vía profundamente democrática burguesa para el desarrollo del capitalismo, a pesar de que fue salvajemente aplastada por el poder colonial español. Fue una verdadera paradoja, porque mientras esta revolución fue derrotada, la de Norteamérica fue victoriosa y unificó en una Federación a las treces colonias, las cuales debieron esperar ocho décadas para optar la vía del desarrollo del capitalismo, porque se dedicaron más bien al mantenimiento y expansión de la esclavitud en los estados del sur.

En la primera mitad del siglo XIX y acicateada por los movimientos anteriores, se llevan a cabo las guerras de independencia en América Latina. Como guerras de independencia, triunfaron porque derrotaron al conquistador español, pero como revolución democrática burguesa fracasaron, entre otras cosas, porque no se convirtieron en una revolución latinoamericana para constituir una sola nación con una única base de apoyo; por el contrario, de esos procesos solo surgieron Estados nacionales, dirigidos por las oligarquías locales.

Lo anterior ocurrió a pesar de la genialidad del proyecto de Bolívar, quien aspiraba a la unificación de las antiguas colonias y la formación de una única nación, que fuera capaz de generar una unidad que contrarrestara el ímpetu que iba adquiriendo el vecino país del Norte. Pero al no darse esta unidad, Norteamérica terminó dominando y sometiendo a toda América Latina. 
Ocho décadas después de la primera revolución latinoamericana los Estados Unidos vivieron una verdadera guerra revolucionario por la reunificación nacional y la abolición de la esclavitud: por un lado los estados del norte con su capitalismo y trabajo asalariado, y, por otro lado, los estados de secesionistas del sur, con su capitalismo y explotación esclava.

Esa guerra fue la clave no solo de la unidad nacional norteamericana sino también la apertura para que la vía del desarrollo capitalista democrático e independiente venciera a la vía oligárquica y dependiente. Si la historia no se hubiese realizado y escrito de esta manera, los Estados Unidos hoy no serían lo que son, y, lo más seguro es que ese país sería hoy dependiente del capitalismo mundial como país periférico.

Mientras eran derrotados los estados esclavistas del sur en los Estados Unidos, en América Latina las oligarquías de Brasil, Argentina y Uruguay con el apoyo de Inglaterra, primera potencia del mundo de entonces, desataron contra Paraguay una guerra genocida derrotando de esa manera la vieja tentativa de desarrollar un capitalismo independiente, una vez finalizadas nuestras guerras de independencia.

De esa manera, es la vía reaccionaria-oligárquica del desarrollo del capitalismo la que triunfa en América Latina, justo en el momento en que en el sistema mundial la fase imperialista abría un nuevo período de la historia.

El curso posterior de la historia en América Latina demostró que las tareas democráticas no resueltas por las burguesías ni por ninguno de los sectores o fracciones serían asumidas por las 
clases revolucionarias si lograban establecer su propio poder. Ya la Comuna de París lo había anunciado, en 1871, fecha en la cual la revolución democrático-burguesa había terminado.

Al mismo tiempo, entre los revolucionarios latinoamericanos de la época continuó la idea de la gran patria latinoamericana en el momento en que hacía transición el capitalismo hacia el imperialismo. Entre esos revolucionarios el más destacado sin duda, fue el cubano José Martí quien inició y dirigió la guerra por la independencia de su país la cual se continuaría con la de Puerto Rico y en forma progresiva con otros países de América Latina. La fuerza arrolladora de estos movimientos frenó el expansionismo americano, eliminó al colonialismo español y evitó nuevas colonias de Estados Unidos de América.

El único líder que se le anticipó a Martí fue Bolívar cuando planteó la unión latinoamericana para contrarrestar la que se estaba formando en el norte. Pero las épocas fueron distintas, porque cuando Bolívar inició su lucha, los Estados Unidos se expandían hacia las costas del Pacífico expropiando a los indios, y la Gran Bretaña era la primera potencia del mundo capitalista. $Y$ cuando Martí luchaba por la independencia de Cuba, Estados Unidos transitaba al imperialismo con sus monopolios capitalistas, hegemonizando el dominio en los países del Caribe y disputando a Europa las tierras de Suramérica. Es decir, lo que Bolívar vivió como posibilidad futura, Martí lo vivió en su presente.

Se podría decir que lo que Bolívar no hizo, Martí pretendió realizarlo, igualmente, a escala latinoamericana, pero combatiendo los rezagos coloniales que aún se vivían en el seno de los países ayer colonizados. 
Sus ideas de integración y unión no prosperaron con los países liberados en las décadas siguientes ¿Se podría decir, entonces, que Bolívar y Martí araron en el desierto?

Ello no es del todo cierto, porque ese legado que aún no se ha hecho realidad está allí. Siempre presente. A la muerte de Martí, se esperaba que con el surgimiento de los primeros partidos socialistas y comunistas en América Latina, como efecto de los procesos revolucionarios en Occidente, se rescatara ese legado para hacerlo realidad. Pero pronto fue abandonado salvo pocas excepciones, entre ellas algunos bolivarianos y martianos como Julio Antonio Mella quien estimulado por la revolución de octubre se adhirió al movimiento comunista, aunque no fue tarde su desilusión.

Era la época en que la Unión Soviética, bajo el estalinismo, subordinó a todos los partidos comunistas del mundo bajo la estrategia equivocada de construir el socialismo en un solo país. Esta concepción fue duramente cuestionada por León Trotsky, quien con la concepción de que sería imposible la construcción del socialismo en un solo país, apostaba a la revolución permanente, a través de un frente único antiimperialista con la alianza de todos los revolucionarios. Fueron dos concepciones diferentes que se enfrentaron: la estalinista y trotskista. El estalinismo rechazaba la idea de la unidad latinoamericana haciendo macartismo en contra de quienes la planteaban señalándolos de nacionalistas, pequeños burgueses y reformistas. El trotskismo por el contrario, consideraba que era necesaria la integración de los países latinoamericanos y que esa lucha era inseparable de la lucha por la independencia nacional. Esta corriente entendía que solo un frente revolucionario amplio con variantes democráticas podría alcanzar el objetivo. 
Era clara la concepción de Trotsky cuando señalaba que los mismos esfuerzos de Norteamérica de unificar a la mitad del norte del continente eran utilizadas para desunir, debilitar y esclavizar a la mitad del sur. Pero iba aun más lejos: el atraso y la esclavitud se liquidarían si el joven proletariado suramericano dirigiendo a las masas oprimidas contra la intrigas del imperialismo mundial, luchaba por el socialismo en los Estados del sur y Centroamérica formando una gran federación. En la concepción de Trotsky solo unos estados unidos socialistas de sur y centro América, podrían darle viabilidad a la consigna marxista: proletarios de todos los países unidos.

\section{LA FILOSOFÍA DE LA LIBERACIÓN Y LA SEGUNDA EMANCIPACIÓN}

Dussel (2007) considera que en América Latina el giro descolonizador desde el pueblo hacia la segunda independencia arranca en 1959, haciendo la salvedad que en América Latina la izquierda en general se ha movido desde una posición eurocéntrica hacia el descubrimiento del pueblo concreto, histórico, oprimido y excluido, constituyéndose en referencia principal de su qué-hacer político (p.482).

Al marxismo le ha costado mucho, a través de la historia, articular su pensamiento con las corrientes populares, pues de una manera dogmática sus diferentes vertientes han considerado a la clase obrera como sinónimo de pueblo.

Sin embargo, algunas corrientes de pensamiento en el continente, muy proclives a la influencia del marxismo, como la liderada por Juan Carlos Mariátegui y Farabundo Martí y otros movimientos históricos de los diversos países, que culminaron en 
la Revolución cubana, significaron una mayor comprensión del sentido de lo popular.

Algunas ideas importantes en el rescate de la categoría pueblo la encontramos en Juan Bautista Justo (1865-1928), fundador del Partido Socialista de Argentina al que presidió hasta su muerte. Justo, quien mezclaba el biologismo spenceriano con Marx, consideraba la teoría del plusvalor como «una mera alegoría». Justo (1973), en su momento escribía (citado en Dussel, 2007): "el pueblo argentino no tiene glorias: la independencia fue una gloria burguesa, el pueblo no tuvo más parte en ella que servir a los designios de la clase privilegiada que dirigía el movimiento" (p.483). Indicaba con ello Justo que la primera Emancipación fue efectuada bajo el liderazgo de la oligarquía criolla, mientras que la segunda debería ser conducida por el pueblo mismo.

José Martí (1853-1895) fue otro pensador que le dio a la categoría de pueblo su real dimensión en las luchas de liberación que logró emprender y dirigir, entre el final de las guerras de la Independencia del comienzo del siglo XIX contra España y el inicio de la confrontación contra el coloso del Norte, proceso que denominaba la «segunda Independencia».

Por ser un gran viajero por Europa, América Latina, el Caribe, y haber permanecido quince años en Estados Unidos, decía Martí (1977): "Viví en el monstruo, y le conozco las entrañas" (p.322). Como un nuevo Jonás, tuvo el conocimiento y la experiencia para descubrir en plena lucha por la emancipación de la Cuba colonial el hecho masivo del nuevo neocolonialismo en el que caían uno tras otro los países latinoamericanos, desde México a Argentina. Nadie como él vislumbró la nueva etapa en la que América Latina 
no ha hecho sino internarse durante más de un siglo en una creciente dependencia de Estados Unidos con todas las consecuencias negativas que el mismo Martí no pudo quizá imaginar.

Frente a James Gillespie Blaine (1830-1893), presidente de la Cámara de Representantes de los Estados Unidos años, que hablaba de Our America (como toda América para los Estados Unidos), Martí antepone Nuestra América, aunque sabe que el gigante del Norte ha comenzado a tejer la tela de araña. En 1881, comentando el Congreso Internacional de Washington (con el que se iniciaba el panamericanismo como ideología norteamericana de penetración en América Latina) escribe: "Fue aquel invierno de angustia, en que por ignorancia, o por fe fanática, o por miedo, o por cortesía, se reunieron en Washington, bajo el águila temible, los pueblos latinoamericanos" (Martí, 1891, p.143).

Su claridad conceptual, muy por encima de otros dirigentes de la época, lo llevó a cuestionar el eurocentrismo ya imperante en la mentalidad de las élites criollas:

Los políticos nacionales han de reemplazar a los políticos exóticos, injértese en nuestras repúblicas el mundo: pero el tronco ha de ser el de nuestras repúblicas. Y calle el pedante vencido; que no hay patria en que pueda tener, el hombre más orgullo que en nuestras dolorosas repúblicas americanas [...] Éramos una máscara, con los calzones de Inglaterra, el chaleco parisiense, el chaquetón de Norteamérica y la montera de España. El indio, mudo, nos daba vueltas alrededor, y se iba al monte, a la cumbre del monte, a bautizar a sus hijos. Éramos charreteras de togas, en países que venían al mundo con alpargata en los pies, y la vincha en la cabeza (Martí, 2005, p.34). 
Pero a pesar de esa claridad, sobre la dominación neocolonial y sobre el eurocentrismo, no tuvo conciencia clara de lo que el capitalismo significaba, porque no conocía suficientemente la obra de Marx. Por el contrario, Mariátegui (2007) autor de Siete ensayos de interpretación sobre la realidad peruana, sabe lo que significa el capitalismo, y sus estudios sobre el marxismo le van a permitir descubrir en el entramado de relaciones el problema central social peruano desde el punto de vista materialista crítico.

Su realismo crítico creativo, se despliega en torno al problema indígena, es decir, a lo popular propiamente latinoamericano en el Perú. Reflexiones sobre el indigenismo que le permitieron a los marxistas dogmáticos de su época considerarlo un populista, no vislumbraban que el problema indígena en Perú era asociable con el del campesino en Rusia que Lenin nunca pudo resolver. Pero ello era explicable, porque los partidos comunistas fundados en América Latina desde 1919 eran cabalmente eurocéntricos, mientras que para Mariátegui (2007), en cambio, el marxismo no era la mera aplicación dogmática de categorías abstractas a una realidad concreta histórica, sino al revés, pues la tarea consistía en la construcción de las categorías necesarias a partir de dicha realidad concreta.

Mariátegui (2007) interpretó la época colonial y su régimen como feudal, con un sistema económico-político que dio la espalda al pueblo peruano, a las comunidades indígenas. Es bueno anotar que ya para la época esta caracterización era polémica, pues algunos pensadores consideraban que el régimen establecido en estas latitudes respondía no a los intereses del feudalismo sino a los del capitalismo comercial europeo. Tal vez la mejor caracterización al respecto la va a hacer el historiador chileno Bagú (1949) con su análisis sobre la economía colonial. 
Mientras Mariátegui se preocupó por incidir en el imaginario popular, en su narrativa histórica, en su memoria, en sus luchas, en sus esperanzas, la izquierda racionalista y dogmática despreció ese imaginario, que siempre es narrativamente religioso, y que la sobreestimación de un cierto ateísmo negó abstractamente, sin caer en la cuenta, que según Dussel (2007).

(...) ese imaginario hay que saberlo releer, reinterpretar, relanzar para transformar a los miembros de ese pueblo en actores, como «los esclavos que se liberan en Egipto», metáfora exótica, usada por Túpac Amaru, los emancipadores, Fidel Castro, los sandinistas, Rigoberta Menchú y tantos otros. (p.482).

Por ello, como Martí, también Mariátegui (1929) nos habla de la «segunda independencia»:

Pero las burguesías nacionales, que ven en la cooperación con el imperialismo la mejor fuente de provechos, se sienten lo bastante dueñas del poder político para no preocuparse seriamente de la soberanía nacional. Estas burguesías [...] no tienen ninguna predisposición en admitir la necesidad de luchar por la Segunda independencia". (p.1).

Como lo indica Dussel (2007):

Mariátegui tenía razón en sus observaciones políticas, pues el antiimperialismo nacionalista era hegemonizado por la burguesía nacional postcolonial, y en el mejor de los casos, en lucha de competencia contra la burguesía del centro del sistema capitalista mundial. Es decir, en tanto tenían a los oprimidos y excluidos como aliados coyunturales esa lucha antiimperialista burguesa era populista y no popular, porque para que tuviera esta connotación se requería al pueblo 
no como simple aliado, sino como momento del bloque histórico de poder. Para que la lucha sea popular, se requiere además de ser antiimperialista, ser antiburguesa y anticapitalista. (p.485)

Por ello, desde un punto de vista estrictamente marxista, la obra de Bagú (1949), Economía de la sociedad colonial significa la ruptura epistemológica más importante en el siglo XX latinoamericano (habrá que esperar hasta la década de los sesenta con la «teoría de la dependencia» para observar otro momento teórico de semejante envergadura). Al respecto dice Bagú, como se lee en Lowy (1980):

Lejos de revivir el ciclo feudal, América ingresó con sorprendente celeridad dentro del ciclo del capitalismo comercial, ya inaugurado en Europa. Más aún: América contribuyó a dar a ese ciclo un vigor colosal, haciendo posible la iniciación del período del capitalismo industrial, siglos más tarde. La esclavitud no tiene nada de feudal y sí todo de capitalista [...]. La mano de obra indígena y la otra de procedencia africana fueron los pilares del trabajo colonial americano. América y África -destilaron su sangre por los alquimistas del comercio internacional- fueron indispensables para el deslumbrante florecimiento capitalista europeo. (p.229)

Al respecto, la posición de Dussel (2007) es más radical:

Si es verdad que antes de 1492 habíase «ya inaugurado en Europa» algunas formas de producción que serán subsumidas en el sistema capitalista, es sólo por la apertura al Atlántico y por la acumulación originaria proveniente de América Latina como nace el capitalismo como tal. Es decir, esa acumulación y la ampliación territorial, poblacional y 
de riqueza minera primeramente obtenida en América no producirá simplemente «el capitalismo industrial siglos más tarde», sino que originarán ipso facto al capitalismo mercantilista, es decir, el capitalismo en cuanto tal (y también posteriormente condicionarán el desarrollo del capitalismo industrial, imperialista y transnacional. (pp.487-488)

\section{LA REVOLUCIÓN CUBANA}

Fue la primera revolución triunfante en América que logró la liberación del imperialismo e inició un programa revolucionario para cumplir con las tareas democráticas, aún pendientes.

Se produjo en una coyuntura favorable de la guerra fría, cuando el poder mundial era compartido -lo que permitía un cierto movimiento geopolítico- por la bipolaridad de Estados Unidos y de la Unión Soviética. Esa coyuntura bipolar tuvo corta vida, unos cuarenta y cuatro años (1945-1989). El derrumbe de la Unión Soviética y del socialismo en la Europa oriental modifica sustancialmente el horizonte político mundial y especialmente el latinoamericano.

En esta -como en todas las revoluciones- hubo figuras singulares, liderazgos que condujeron un proceso popular, que constituyen la referencia simbólica del movimiento histórico y que cobrarán más importancia al correr de los decenios. En este caso se trata de dos personajes históricos que han penetrado en el imaginario popular latinoamericano: Ernesto «Che» Guevara y Fidel Castro.

Resalta en el caso de Fidel Castro (1926-2016...), hijo de un terrateniente de origen gallego, las intuiciones que guiaron su 
acción política estratégico-revolucionaria, desde antes de que asumiera la ideología marxista:

No nací pobre, nací rico; no fui campesino sin tierra, sino el hijo de un terrateniente; no viví en un bohío con piso de tierra ni anduve descalzo. Vi de cerca la pobreza sin llegar a sufrirla. Por eso [conclusión que habría que explicar normativamente] no soy un defensor de los terratenientes sino del pueblo, de los campesinos. [...] La revolución fue más poderosa: inculcó la fe al pueblo, y la dictadura [de Batista] sucumbió. Castro (1975), citado en Dussel, s.f., p.13

Siguiendo con el tema, Castro, ("La historia me absolverá") con una cualidad de revolucionario, también antepone la sinceridad al engaño. En este sentido hay que hablar sin ningún temor y con toda claridad al pueblo precisamente para que no haya ninguna decepción. En esto se diferenciaba de los políticos tradicionales que con tal de alcanzar sus pretensiones o precisamente para ello, lo hacían engañando al pueblo prometiéndole milagros para obtener su apoyo.

Es como el concepto de fetichismo en Marx, que lo había adoptado antes de su opción por el comunismo. Son actitudes políticas sustantivas y profundamente normativas. La coherencia ética del político se funda en una clara opción por el pueblo, que debe distinguirse de la posición populista. En el «Discurso de la Victoria», Castro (1959) insiste sobre lo mismo: "Decir la verdad es el primer deber de todo revolucionario, engañar al pueblo despertándole engañosas ilusiones, siempre traería las peores consecuencias".

Es importante observar que nunca Fidel Castro se refiere a la lucha de clases conducida por la clase obrero-industrial. Su re- 
ferencia -como todos los líderes de las otras revoluciones socialistas del mundo periférico o postcolonial- es siempre el pueblo, como puede leerse en la Primera declaración de La Habana:

EI pueblo se ha reunido hoy para discutir importantes cuestiones [...] ¿Por qué? Porque nuestro pueblo sabe lo que está defendiendo, nuestro pueblo sabe la batalla que está librando. Y como nuestro pueblo sabe que está librando una gran lucha por su sobrevivencia y por su triunfo, y puesto que nuestro pueblo es un pueblo batallador y un pueblo valiente, por eso están aquí presentes los cubanos $[\ldots]$ Nuestro pueblo tenía derecho a ser un día un pueblo libre, nuestro pueblo tenía derecho a regir un día sus propios destinos, nuestro pueblo tenía derecho a contar un día con gobernantes que no defendieran intereses de privilegiados $[\ldots]$, sino con gobernantes que pusiesen los intereses de su pueblo y de su patria por encima de los intereses del extranjero voraz; con gobernantes que pusiesen los intereses del pueblo [y aquí Castro especifica las reivindicaciones de las identidades colectivas que constituyen el pueblo], los intereses de sus campesinos, los intereses de sus obreros, los intereses de los jóvenes, los intereses de los niños, los intereses de las mujeres, los intereses de los ancianos, por encima de los intereses de los privilegiados y los explotadores. (Castro, 1960, p.1)

Eso fue lo que encontró la revolución al llegar al ejercicio delegado del poder: un país económicamente subdesarrollado, un pueblo que era víctima de todo género de explotación.

Son claras definiciones de una política de liberación, que sitúa la soberanía en la comunidad política, en el pueblo y no en el 
Estado. De la misma manera es la vida del pueblo la instancia normativa política, como se lee en Castro (1960, p.2):

¿Qué quiere decir iPatria o Muerte!? Quiere decir que a cualquiera de nosotros no le importa morir con tal de que su pueblo viva, de que su patria viva; que a ninguno de nosotros nos importa entregarle nuestra vida a la patria, para que la patria siga viviendo.

Para la filosofía de la liberación el pueblo no es una clase social. Esta se determina en el «campo» económico o en el «ámbito» social, y por tanto es esencialmente una categoría económica o sociológica. Mientras que pueblo es una categoría estrictamente política y constituye una identidad colectiva, una comunidad política o un bloque social que atraviesa momentos del campo económico (modos de producción, por ejemplo) o político de la historia de un país, de una patria, de un Estado en sus múltiples etapas.

De la misma manera, hay que redefinir al Estado. Este no es un instrumento necesario de dominación -contra los anarquistas extremos-.

Por el contrario, lo que ha ocurrido, sencillamente, es que ese instrumento que se llama Estado y todos sus órganos de poder, aunque puede ser que le quede todavía alguna que otra mano al servicio de esos privilegios, iese Estado es hoy un instrumento de poder al servicio de los oprimidos y de los explotados de la patria!

Como señala una de las tesis políticas de Dussel (2006) mientras unos «mandan mandando», cuando el poder institucionalizado se fetichiza y por ello «dominan»; otros, en cambio, «mandan obedeciendo», cuando el ejercicio delegado del poder se cumple como «servicio» obediencial. 
Guevara (1974) marxista mucho antes que Fidel Castro, más teórico que este (aunque menos político), advierte otros aspectos innovadores de la Revolución cubana cuando expresa:

Nunca en América se había producido un hecho de tan extraordinarias características [...] a tal extremo, que ha sido calificado por algunos como el acontecimiento cardinal de América [...]. Este movimiento, grandemente heterodoxo, en sus formas y manifestaciones [...]

EI primer aspecto heterodoxo, quizás, el más importante, el más original, es una fuerza telúrica llamada Fidel Castro [...] a nosotros se nos antojan comparables con los de las más altas figuras históricas de toda Latinoamérica [...]. Tiene [un] extraordinario afán de auscultar siempre la voluntad del pueblo. (pp.515-516)

Un segundo aspecto heterodoxo contenido en el mismo texto, consiste en:

[...] la Sierra Maestra, escenario de la primera columna revolucionaria, es un lugar donde se refugian todos los campesinos, que luchando a brazo partido contra el latifundio, van allí a buscar un nuevo pedazo de tierra que arrebatan al Estado o a algún voraz propietario latifundista para crear su pequeña riqueza. Deben estar siempre en continua lucha contra las exacciones de los soldados [...]. Pueden catalogarse como [teniendo un] espíritu pequeño burgués; campesino [que] lucha porque quiere tierra. (Guevara, 1974, pp.517-518).

No era el actor de la revolución ni la clase obrera, como pensaba Marx, ni el campesinado multitudinario chino de Mao Tse-tung. Era el pequeño campesino con aspiración a propietario. Además, 
los mismos revolucionarios de Granma eran pequeños burgueses urbanos, como lo serán los cuadros principales y primeros del sandinismo.

En tercer lugar, continúa Guevara (1974):

Eso es lo que en realidad somos nosotros, los suavemente llamados subdesarrollados, en verdad países coloniales, semi-coloniales o dependientes. Somos países de economía distorsionada por la acción imperial. [Por ello nuestros países] desembocan en la más terrible y permanente hambre del pueblo [...]. El bajo salario, el subempleo, el desempleo: el hambre de los pueblos [...]. Las condiciones objetivas estaban dadas por el hambre del pueblo, la reacción frente a ese hambre [...]. Faltaron en América las condiciones subjetivas de las cuales la más importante es la conciencia de la posibilidad de la victoria. (p.520)

Es decir, es una revolución descolonizadora (o emancipación de un país postcolonial) que asumía la explotación del pueblo que tenía por origen el proceso de la conquista iniciado en 1492 (cuando igualmente se originan el capitalismo mercantil, las metrópolis eurocéntricas y el fenómeno de la Modernidad -de estos dos últimos fenómenos el «Che» Guevara no podía todavía tener conciencia-).

Che-Guevara fue innovador en el descubrimiento de la normatividad (aunque él pensaba que era la ética) en el militante político más que en el profesional burocrático. Criticaba al dogmatismo en que había caído el marxismo (de origen soviético y, por desgracia, rápidamente implantado en Cuba):

En este periodo de construcción del socialismo podemos 
ver el hombre nuevo que va naciendo. Su imagen no está todavía acabada; no podría estarlo nunca ya que el proceso marcha paralelo al desarrollo de formas económicas nuevas [...]. Déjenme decirles, a riesgo de parecer ridículo, que el revolucionario verdadero está guiado por grandes sentimientos de amor. Es imposible pensar en un revolucionario auténtico sin esta cualidad [...]. Todos los días hay que luchar porque ese amor a la humanidad viviente se transforme en hechos concretos. (Guevara, 1971, p.115)

Por desgracia, el puro comentario de los manuales soviéticos y la imposibilidad de desarrollar una política infectó teóricamente a la Revolución cubana. Y como presagiando posibles desvíos, el anterior autor escribió: "En esas condiciones, hay que tener una gran dosis de humanidad, una gran dosis de sentido de justicia y de la verdad para no caer en extremos dogmatismos, en escolasticismos fríos, en aislamiento de las masas" (Guevara, 1971, p.127).

Movida por una profunda vocación latinoamericana, con un programa que conjugaba tareas democráticas y socialistas e inspirándose en el ejemplo martiano, esa revolución impulsó una estrategia de revolución continental, inspirándose en la concepción guevarista de que la revolución no triunfaría en un solo país y que era necesario llevarla a todas las latitudes del continente, creando varios Vietnam en América Latina.

El Che honró sus ideas cuando organizó una guerrilla guevarista en Bolivia, cuyo objetivo era la constitución de un ejército internacional de liberación de todos los países de Suramérica. En su mensaje a la Tricontinental, el Che lo había anunciado y después de haber participado en la revolución congolesa y presen- 
ciado su derrota, seguía insistiendo que frente al primer fracaso no se debía renunciar a la constitución de ese ejército del pueblo.

Mientras se desarrollaba el movimiento revolucionario en Bolivia, en La Habana se realizaba un congreso de organizaciones de izquierda de todos los países de América Latina, con el nombre Conferencia de la organización latinoamericana de solidaridad, al tiempo que según Dussel (2007):

El «Che» prefirió continuar la lucha revolucionaria, y aunque se equivocó geopolíticamente al no ver la diferencia entre Cuba y Bolivia, no se equivocó en considerar que la política, cuando es militancia, vocación y ejemplo de vida, exige entregar la vida «con tal que su pueblo viva» (como ya había expresado antes Castro). Se puede descubrir, entonces, un sentido normativo de la política, que no quita el realismo de la factibilidad política - para el que la teoría estratégica de la guerra de guerrillas significó, por un tiempo, el prototipo de la lucha de la vanguardia-. Su fracaso, debido en gran parte al fortalecimiento militar del Imperio y posterior caída de la Unión Soviética, no le quita que haya sido un momento estelar de un modelo de la acción estratégica -ya que la política de la liberación, como toda política, aprende por errores y aciertos, analizados a posteriori-. (p.494)

\section{LA UNIDAD POPULAR EN EL CHILE DE ALLENDE (1970-1973)}

La Revolución cubana cambia el mapa del campo político latinoamericano. Todos los movimientos en todos los países, e incluso la estrategia del Imperio, modificaron las premisas desde esta primera revolución socialista. En Chile, por su parte, la propuesta de una «revolución en libertad» de la Democracia Cristia- 
na (1964-1970), en reacción frente a la Revolución cubana, abrió -por su fracaso- el camino a la «Unidad Popular» liderada por Salvador Allende (1970-1973) -primer gobierno socialista que llegaba al poder por la vía electoral-. Era un nuevo paso adelante en la novedad política de la izquierda latinoamericana. Era un segundo modelo de transición a la sociedad socialista.

La Revolución chilena, democrática y socialista, saca a la política de la izquierda (aun revolucionaria) del «campo» militar o guerrillero, para dar los primeros pasos en el campo político propiamente dicho, seriamente transformador (en el campo económico y político, y con respecto al sistema capitalista y liberal). Su «peligrosidad» para la hegemonía continental norteamericana fue rápidamente detectada y, dirigida desde el Departamento de Estado, bajo el protagonismo de Henry Kissinger, se impuso el 11 de septiembre de 1973 la dictadura militar de Augusto Pinochet. La «vía chilena al socialismo» fue abruptamente tronchada por la violencia del Imperio. Fue una experiencia histórica del pueblo latinoamericano. Fue la experiencia de una «convergencia con los partidos socialistas (incluso el comunista) y socialdemócratas con las fuerzas cristianas progresistas [como el MAPU fundado por Rodrigo Ambrosio], con todos los grupos democráticos no enfeudados a la propiedad de tipo monopólico». El eurocomunismo en Italia, España, Portugal o Francia, por ejemplo, fue parte del efecto en cascada del caso chileno.

En 1972 se reúne en Santiago el I Encuentro latinoamericano de Cristianos por el Socialismo (bajo la convocatoria de Gonzalo Arroyo y con la presencia del obispo de Cuernavaca Sergio Méndez Arceo). El documento final del encuentro (citado en Silva, 1989) declara que: 
El socialismo se presenta como la única alternativa aceptable para la superación de la sociedad clasista. En efecto, las clases son el reflejo de la base económica que en la sociedad capitalista divide antagónicamente a los poseedores del capital de los asalariados [...] solo sustituyendo la propiedad privada por la propiedad social de los medios de producción se crean condiciones objetivas para una supresión del antagonismo de clase. (p.270)

\section{LA REVOLUCIÓN SANDINISTA (1979-1990)}

César Augusto Sandino fue el gran pensador que sirvió de inspiración a los líderes de este proceso. Es verdad que biográficamente estuvo adherido a una extraña secta (la Escuela magnético-espiritual), que el sandinismo político simplemente ignora con mucho criterio. Sandino interesa políticamente no por su teosofía, sino por la lucha anti-norteamericana y contra la dictadura en su patria que llevó a cabo. Es un referente nacionalista singular. El Frente Sandinista de Liberación Nacional (FSLN) absorbe de todas maneras un cierto espíritu anarquista, ético, del Sandino histórico, corregido por una doble vertiente: desde la doctrina y praxis actualizada por el «Che-Guevara (más que Fidel Castro), y desde la teología de la liberación (que reemplaza a la ambigua «teosofía» del Sandino histórico).

Aunque la revolución había tenido su origen en una insurrección militar, el FSLN permitió el pluripartidismo, la libertad de prensa y la existencia de la oposición.

Lo novedoso de la revolución, por tanto, fue el pluralismo en el impulso cultural y religioso que tocó el imaginario popular como en ninguna otra revolución. Luis Carrión, Jaime Wheelock, Mir- 
tha Valtodano y otros comandantes revolucionarios eran miembros de las juventudes cristianas. Esto cambió cualitativamente el proceso: la campaña contra el analfabetismo, dirigida por Fernando Cardenal: La creatividad cultural estética, también orientada por otro Cardenal, ahora Ernesto; las relaciones exteriores conducidas por Miguel Escoto; la continua movilización de base; la reforma agraria; la solución al problema indígena de la Costa Atlántica (después de iniciales errores), hicieron posible un nuevo tipo de revolución hacia el socialismo. En cualquier caso, el FSLN evitaba palabras tabú como comunismo, marxismo y hasta socialismo. Ramírez (1985, citado en Dussel, s.f.) escribe:

No podemos decir que todas las ideas que mueven al proyecto revolucionario sandinista estaban en la mente de Sandino. Tenemos que pensar que se trata de otra época [...]. La democracia popular puede ser desarrollada por el Frente Sandinista a través de los órganos de poder popular, que son: el gobierno revolucionario, el Consejo de Estado y todas las demás formas de poder popular que la revolución desarrolla en distintos planos y en distintas instancias de la vida nacional [...]. Una vez liberados del dominio extranjero en la vida política nacional, liberados de la influencia de las formas de poder extranjero y liberados del dominio de estas formas paralelas históricas, es posible dar paso por entero a nuevas fuerzas de organización en el país [...]. En lo que se refiere a las ideas de Sandino, se expresa a través del inicio del Programa de Reforma Agraria $[\ldots]^{*}$. (pp.24-25)

Puede verse cómo el FSLN se refiere como a su narrativa fun-

* S. Arce, "Vigencia del pensamiento sandinista", Instituto de Estudios del Sandinismo, 1985, pp.24-25 
damental al pensamiento de Sandino (y no a Marx o Lenin, por ejemplo). Esto permitía una gran autonomía ideológica a la vanguardia (los comandantes de la Revolución), y por ello nunca dejaron que la Unión Soviética (como en Cuba) intentara dirigir teóricamente a la Revolución popular sandinista. Su originalidad era un presupuesto innegociable.

En la visita del papa Juan Pablo II a Managua, la Revolución sandinista lo recibió en la plaza de la Revolución con un gran cartel, en cuya izquierda estaba la figura de Carlos Fonseca y a la izquierda una imagen de la Inmaculada, con la consigna «Entre cristianismo y revolución no hay contradicción», lo que indicaba nuevamente un gran paso adelante en la comprensión del imaginario popular nicaragüense.

Más aún, mucho más que la Revolución cubana, la Revolución nicaragüense cobraba un claro sentido de revolución cultural y hasta religiosa modificando los parámetros ya agotados de la izquierda. Su originalidad fue advertida inmediatamente, aunque quizá nunca fue claramente analizada desde la teoría política hasta el presente. Es decir, y repitiendo, había surgido una «nueva izquierda» latinoamericana, para la cual el antiguo dogmatismo marxista-leninista del socialismo real de la Europa del este carecía de vigencia. La articulación con el pueblo, complejo, histórico, concreto, plural, y con los nuevos movimientos sociales, exigía una nueva filosofía política (Dussel, 2007, p.498).

\section{LA REVOLUCIÓN ZAPATISTA (DESDE 1994)}

Pasaron cinco largos años desde la caída del sandinismo, del muro de Berlín y el derrumbe del socialismo real. La Revolución zapatista parte innovadoramente de un movimiento que, con 
motivo de las celebraciones del mal llamado «descubrimiento de 1992», había permitido a los pueblos originarios del continente repensar sus centenarias reivindicaciones.

Un sector fundamental del pueblo latinoamericano había cobrado conciencia, y se encaminaba con claridad a reactivar distintos movimientos sociales (antiguos o nuevos) para transformar el bloque disperso de muchos movimientos reivindicativos en lo social en un pueblo con conciencia política.

El marxismo tradicional se encontraba indefenso teóricamente. Había que pensar todo de nuevo. Esto suponía agregar al campo cultural (indígena) el aspecto racial (clasificación fundamental en la «colonialidad del poder» mostrada por Aníbal Quijano) e históricopolítico y religioso. Los catequistas del obispo Samuel Ruiz, en Chiapas, se transformarán en comandantes zapatistas, con plena conciencia de su dignidad, autodeterminación, originalidad cultural, religiosa, política, judicial, económica y hasta con técnicas agrícolas, educativas, sanitarias, etc. Es un reclamo que tiene más de cinco siglos y que al fin llega a la superficie del campo político.

Como lo indica Dussel (2007), la izquierda se enfrentará a la provocación quizá más creativa de su historia en América Latina. Ahora se podrá comprender el porqué de la crítica a la comprensión mono-étnica del Estado (todos los ciudadanos deben ser cultural y homogéneamente iguales) o a la definición monolítica de la nación o el pueblo. Esta falacia univoca reduccionista (una nación=un Estado; un pueblo=una identidad colectiva cultural) no se encuentra solo en la tradición política conservadora (criolla dominante), sino que igualmente es defendida por los movimientos asimilacionistas «mestizos», populistas y también por la mayoría 
de la izquierda (en especial, por los antiguos partidos comunistas eurocéntricos), con excepción, por ejemplo, de J. C. Mariátegui (lo que confirma la regia).

Textualmente refiriéndose a este fenómeno, escribe:

EI zapatismo, por ello, pondrá profundamente en cuestión muchas estructuras inconscientes de la simbólica política-cultural de la llamada «cultura nacional del Estado postcolonial» (que comienza a institucionalizarse desde 1810) y abre una experiencia histórica que de ser teóricamente expresada constituirá un nuevo capítulo en la filosofía política mundial. El mismo imaginario popular deberá redescubrir aspectos ocultados, excluidos o invisibles de y para sí mismo. Entre los rostros, los movimientos, las identidades colectivas cuyas reivindicaciones van constituyendo al pueblo (como plebs) no podrán faltar desde ahora las etnias indígenas originarias, que soportaron el genocidio de la expansión de la Modernidad en la conquista, la dominación del Estado postcolonial liberal, del Estado populista benefactor y hasta revolucionario, y, por último, del proyecto globalizador neoliberal, que, como una «aplanadora homogeneizante», pretende que todos los ciudadanos son solo consumidores equivalentes (si son solventes, es decir, si no son pobres, sin dinero, porque en este caso son expulsados al reino de la «nada», del «no ser» parmenídico, prescindibles, desechables) de un mercado global e idéntico en sus contenidos. Los más pobres entre los pobres cultural, económica y políticamente, es decir, los más distintos entre los Diferentes, nos permiten recortar con mayor precisión desde abajo y desde fuera todos los estratos restantes del nombrado pueblo. (Dussel, 2007, p.499) 
El zapatismo era, desde el comienzo, una revolución dentro de las revoluciones, y la revolución de las mujeres zapatistas una revolución dentro del zapatismo y del pueblo maya. El proceso de liberación hacia los opresores de fuera comenzaba por el enfrentamiento con las opresiones tradicionales de dentro. La mujer maya, aunque mucho menos dominada que la ladina, sufría opresiones antiguas. El proceso emancipador se generalizaba y comenzaba por «limpiar la propia casa». Las primeras beneficiadas fueron las mismas mujeres zapatistas, que desde comandantes hacia abajo cumplirían todas las tareas que exige la revolución, funciones antes solo efectuadas por varones.

Así, pues, los guerrilleros vieron, durante los años del nacimiento del EZLN y de la clandestinidad cómo caían una a una sus convicciones, mientras se afirmaban las formas comunitarias indígenas de entender la política y la guerra al ingresar cada vez más indígenas en las fuerzas insurgentes. Llega un momento en que el EZLN, en este acercarse y acercarse, ya no puede tomar decisiones, primero sin darle a conocer a las comunidades lo que va a hacer para que estén enteradas, y luego, sin quererlo, en un proceso que también ahorita podemos reflexionar pero que entonces fue irreflexivo: a pedirles permiso. Es cuando yo digo que hubo un choque y que en ese choque perdió la organización político-militar, perdió la toma de decisiones unipersonales y verticales, frente a la toma de decisiones colectiva y horizontal (Moreno, 2005).

Y aclaran todavía:

De hecho nosotros nos organizamos así porque es la (única) forma que nos dejaron [obrar la comunidad maya...]. Nosotros no pretendemos ser la vanguardia histórica, una, 
(única y verdadera). Nosotros no pretendemos aglutinar bajo nuestra bandera zapatista a todos los mexicanos honestos. Nosotros ofrecemos nuestra bandera. Pero hay una bandera más grande y poderosa bajo la cual podemos cobijarnos todos. La bandera de un movimiento nacional revolucionario donde cupieran las más diversas tendencias. (Moreno, 2005)

En el mundo maya, zapatista, se pondera y se hace sublime la dignidad:

No dejemos que nuestra dignidad sea ofertada en el gran mercado de los poderosos! Si perdemos la dignidad, todo perdemos. Que la lucha sea alegría para los hermanos todos, que se unan a nuestras manos y nuestros pasos en el camino de la verdad y la justicia. (Moreno, 2005, p.14)

Como lo reafirma Dussel (2007):

La dignidad no es lo valioso ni el valor; es el fundamento de todos los valores, La dignidad no es necesario afirmarla cuando no es negada; solo cuando es negada es necesario defenderla y proclamarla.

En el reconocimiento del Otro lo primero que debe ser afirmado es lo sagrado de su subjetividad distinta. Sin dicho reconocimiento no es posible el diálogo, el acuerdo, el establecimiento de un campo político justo. El movimiento exige antes que nada dicha afirmación. (p.502)

El Movimiento zapatista no aparece con fuerza desde el año 2006, año en que sacudió con violencia a la región de Chiapas y la mostró al mundo entero. El hecho de que hayan desaparecido 
del foro público no quiere decir que no existan. En diciembre del 2013 declaró el comandante Marco: hace frío como hace 20 años y como entonces, hoy, una bandera nos cobija: la de la rebeldía.

En los pocos años transcurridos del siglo XXI las experiencias latinoamericanas y en otros horizontes del mundo actual nos han permitido profundizar en la reflexión, $y$, sobre todo, detectar un «estado de rebelión» del pueblo latinoamericano que va tomando dimensiones históricas. No es ya como en 1959 la experiencia de un solo pueblo (el cubano) que se libera, en referencia a las figuras emblemáticas de Ernesto «Che» Guevara y de Fidel Castro. No se trata solo de Salvador Allende, asesinado por un golpe de Estado decidido por Henry Kissinger en persona. Ni siquiera la Nicaragua del FSLN (1979), que aunque intentó la «segunda Emancipación» del Imperio del norte, fue derrotada por la contrarrevolución de los «contras», organizada por el mismo Imperio.

Hoy contemplamos un movimiento popular que a pesar de todas las limitaciones se abre paso en contra de políticas oligárquicas y antiimperiales en América.

Por ello es necesario desarrollar creativamente una filosofía política que sepa expresar ese profundo «estado de rebelión», uno de cuyos escenarios es el Foro Social Mundial de Porto Alegre.

Y como lo señala Dussel (2007):

La Política de la Liberación tiene a esta pluralidad social y política -siempre en formación desde abajo- como referente principal: el pueblo latinoamericano en movilización histórica que nos exige como intelectuales cumplir con el deber de producir una teoría orgánica desde dentro de ese proceso de liberación en marcha. (p.505) 
La idea de que América Latina será una sola patria sigue estando latente en el ambiente intelectual y revolucionario del continente. Igualmente la estrategia de una revolución continental, sobre todo, en las actuales condiciones creadas por la globalización capitalista neoliberal y el poder hegemónico del imperialismo norteamericano.

Enmarcadas por esas ideas existen dos tesis que, a manera de preguntas, se han lanzado para la reflexión de los intelectuales revolucionarios del mundo y del continente:

¿América Latina para ser una sola nación tendrá que ser socialista, o viceversa, para ser socialista tendrá que ser una sola nación?

¿Será que después de más de 100 años de Martí y más de 50 del heroísmo guevarista, es posible pensar en un proceso de revolución permanente para alcanzar una segunda, verdadera y definitiva independencia?

\section{REFERENCIAS BIBLIOGRÁFICAS}

Bagú, S. (1949). Economía de la sociedad colonial. Ensayo de historia comparada de América Latina. Buenos Aires, Argentina: El Ateneo.

Dussel E. (2007). Política de la liberación. Historia mundial y crítica. España: Trotta.

Dussel, E. (2006). 20 Tesis de Política. Ciudad de México, México: Siglo XXI.

Dussel, E. (s.f.) El "giro descolonizador" desde el pueblo y hacia la segunda emancipación. Recuperado de http://biblioteca.clacso.edu.ar/ar/libros/mexico/xochimil/coloquio/Docs/ Mesa4/Enrique\%20Dussel\%202.pdf 
Guevara, E. (1971). El socialismo y el hombre en Cuba. México: Grijalbo.

Guevara, E. (1974). Cuba: ¿excepción histórica o vanguardia en la lucha anticolonialista? Recuperado de https://www.marxists. org/espanol/guevara/escritos/op/libros/presente/09.htm

Lowy, M. (1980). El marxismo en América Latina del 1909 a nuestros días (Antología). México: Ediciones Era.

Mariátegui, J. (1929). Punto de vista antiimperialista. Recuperado de http://criticamarxista-leninista.blogspot.com.co/2013/03/ populismo-antiimperialismo-revolucion-proletaria.html

Mariátegui, J. (2007). 7 ensayos de interpretación de la realidad peruana. Recuperado de http://www.granma.cu/granmad/ secciones/26-julio-2011/de-jose-marti/articulo-14.html

Martí, J. (1981). Versos sencillos, prólogo. Recuperado de http:// www.jose-marti.org/jose_marti/obras/poesia/versossencillos/ 01 versossencillosintro.htm

Martí, J. (2005). Nuestra América. Venezuela: Editorial Ayacucho. Martí, J. (s.f.) Carta a Manuel Mercado, el 18 de mayo de 1895, en: Granma. Recuperado de: http://www.granma.cu/granmad/secciones/26-julio-2011/index.htmIS.M.D

Partido comunista de Cuba (2017). Primera declaración de La Habana. Recuperado de http://www.pcc.cu/pdf/documentos/ otros_doc/primera_declaracion_habana.pdf

Portal Cuba. (2017). Discurso pronunciado por el Comandante Fidel Castro Ruz, en el Parque Céspedes de Santiago de Cuba. Recuperado de http://www.cuba.cu/gobierno/discursos /1959/esp/f010159e.html

Portal Cuba. (2017). Discurso pronunciado por el comandante Fidel Castro Ruz, primer ministro del gobierno revolucionario, en la magna asamblea popular celebrada por el pueblo de Cuba en la Plaza de la República. Recuperado de http://www.cuba. cu/go bierno/discursos/1960/ esp/f020960e.html 
Prensa Latina (2017). La historia me absolverá. [Entrada de blog] Recuperado de http://www.prensa-latina.cu/Dossiers/Moncada/Imagenes/historiameabsolvera.pdf

Silva, (1989). El pensamiento cristiano revolucionario en América Latina y el Caribe. Implicaciones de la teología de la liberación para la sociología de la religión. Recuperado de http://www. ensayistas.org/critica/liberacion/varios/silvagotay.pdf 